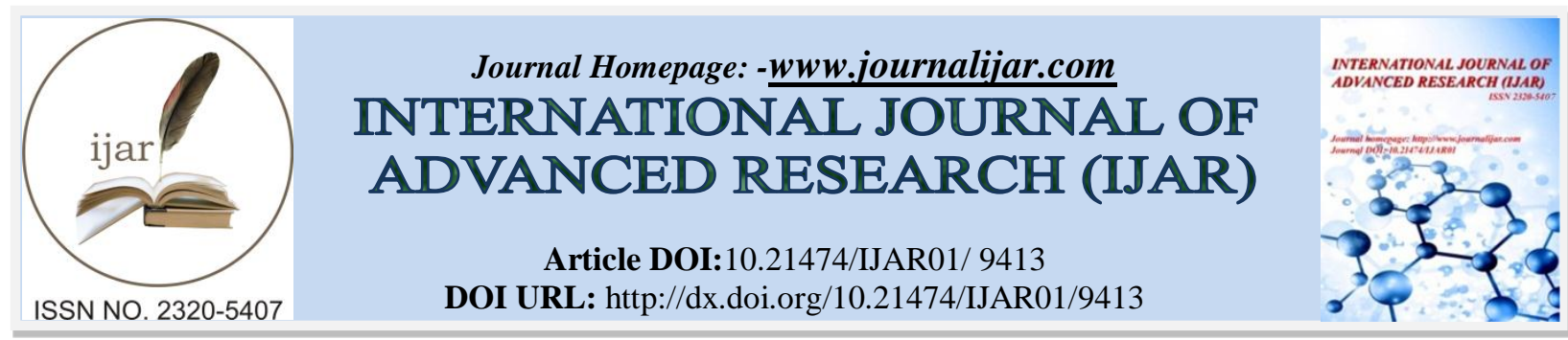

RESEARCH ARTICLE

\title{
HANDHELD ELECTRONIC NOSE (HEN) FOR DETECTION OF OPTIMUM FERMENTATION TIME DURING TEA MANUFACTURE AND ASSESSMENT OF TEA QUALITY.
}

N. Manigandan ${ }^{1}$, V. A. Shanmugaselvan ${ }^{2}$ and P. Surendar ${ }^{1}$.

1. Tea Technology Division, UPASI Tea Research Foundation, Regional centre, Coonoor, , Tamil Nadu, India 643101.

2. Nova lab, Hosur, India.

\section{Manuscript Info}

Received: 20 May 2019

Final Accepted: 22 June 2019

Published: July 2019

Key words:-

CTC, Fermentation, Orthodox, Quality and Tea.
Manuscript History

\begin{abstract}
Fermentation is an important process in tea manufacturing cycle and proper fermentation of tea leaves determines the quality of made tea. Both over and under fermentation affects the quality of made tea. To understand the optimum fermentation time and flavour of the processed tea, CDAC Kolkata had developed a hand held electronic nose system (HEN). The system consists of top, mid and bottom section. Top section contains major portion of electronics, display, pump, sensor array and battery. The detachable mid section holds the valve and provides an air path between pump and sample holder and between sample holder and sensor array. The bottom section is a threaded glass jar that acts as the sample holder. The HEN can be handy in determining the optimum fermentation end point during manufacturing process and to assess the quality of processed tea based on its aroma. Fixed quantity (half of the sample holder) of sample was taken from fermentation bed at an interval of five minutes and the generated aroma volatiles were discharged to the sensor array. The captured aroma was plotted against time to get the second aroma peak, which determined the optimum end point of fermentation. This was compared with the existing chemical method. The results obtained through HEN were correlated with the existing chemical method. The processed teas consisting CTC and orthodox types of manufacture and different grades were evaluated through HEN and the results were compared with organoleptic evaluation of tea by national and international tea tasters. The results revealed that the Handheld Electronic Nose is a suitable instrument for determining the optimum fermentation time during tea manufacture based on aroma.
\end{abstract}

Copy Right, IJAR, 2019,. All rights reserved.

\section{Introduction:-}

Tea is the most consumed beverage in the world next to water. Tea plant is cultivated in more than thirty countries. India is the world's largest consumer, second largest producer and fourth largest exporter of tea. Tea is obtained from tender shoots of plant Camellia sinensis (L.) O. Kuntze, mainly from three varieties sinensis, assamica and cambod, with diverse processing methods to produce various types of teas. Both orthodox and CTC (Crush, Tear

Corresponding Author:-N. Manigandan.

Address:-Tea Technology Division, UPASI Tea Research Foundation, Regional centre, Coonoor, , 
and Curl) in black tea, green, oolong, white and pu-erh are the most widely consumed beverages in the world (Graham,1992). Differences in the chemical composition of teas are attributed to differences in growth, harvesting time and climate, cultivars, soil and geography and differences in processing. The chemical composition of tea is also known to change during fermentation (Chow and Kramer, 1990). In particular, marked changes in composition have been reported in pu-errh tea, which is completely fermented for long time preservation or aging (Ku, Kim, Park, Liu and Lee 2010). The chemical constituents of green, oolong and white teas may depend on the intrinsic chemical composition of fresh tea leaves because the production of these teas involves minimal processing.

Fermentation decides the type of tea. Black tea is fully fermented, Oolong tea is partially fermented while green tea and white teas are unfermented. Fermentation is very important process in black tea manufacture. It refers to the series of chemical reactions results in the browning of tea leaves and the production of flavor and aroma compounds in made tea. Theaflavins and thearubigins are formed by enzymatic oxidation of catechin and their gallates during the fermentation/oxidation stage of tea processing. The characteristic quality attributes of black tea are theaflavins (TF) and thearubigins (TR), which are largely responsible for briskness, brightness, strength and colour (Biswas and Sarkar 1973; Yang and Liu 2013). The variability of total as well as the fractions of theaflavin and thearubigin of different regions may be attributed to factors such as type of cultivar, environment, soil and method of processing. Thearubigins are polymeric compounds derived from polyphenols and their structures are still not well elucidated. Thearubigins are thought to be formed from theaflavins, therefore, prolonged oxidation/ fermentation during tea manufacture results in less theaflavins and more thearubigins (Robertson 1992). Considering polarity/molecular weight, (Roberts and Smith 1963) separated thearubigins in two large groups, viz., low molecular weight theaflavins and high molecular weight theaflavin. Theaflavin contributes $35 \%$ of total colour. It is responsible for taste, tone of colour, body and strength of the brew. A total soluble solid (TSS) is an important physico-chemical parameter of black tea quality (Buyan et al. 2009) and has been regarded as an international standard for quality control (Yao et al. 2006). Total soluble solids consists several biochemical compounds such as polyphenols, sugars, caffeine, amino acids and minerals (Harbowy and Balentine 1997). A high content of total soluble solids in brew is an indication of good quality tea (Wood et al.1964). Significant relationship between theaflavins and tasters quality was established for Kenyan tea (Owuor et al. 2006). The relationship of thaflavins and thearubigins with taster's quality was reported for black tea from the geographical regions of Northeast India (Bhuyan et al. 2009, 2013). Organoleptic evaluation of tea is a vital process to correlate the effects of biochemical components for assessment of quality. Evaluation is carried out by skilled and experienced tasters who determine the market value of tea on a purely subjective basis. Four important liquor characteristics of brew are brightness, briskness, strength and quality. Flavour is important quality parameter of tea which determines its taste and aroma.

The study of Electronic nose and vision and Handheld electronic nose (HEN) on detection of fermentation time during tea manufacturing process and assessment of quality of tea based on its aroma is limited. To the best of our knowledge there is no reported data on detection of fermentation time during manufacturing process and assessment of quality of tea based on its aroma through handheld electronic nose. Therefore, in this study an attempt was made to understand the impact of handheld electronic nose on detection of fermentation time and assessment of quality of black tea based on its aroma when compared with the chemical method.

\section{Materials And Methods:-}

The trial was carried out on CTC (Crush, Tear and Curl) type of manufacturing with about $75 \%$ fine leaf standard. Orthodox teas were collected from different factories of south India.

Withering:

Harvested shoots comprising the standard three leaves and a bud were spread at the rate of $3 \mathrm{~kg} / \mathrm{sq} . \mathrm{ft}$ on a withering trough and artificial wither was given using ambient air for a period of 16-18 hrs.

\section{CTC Rolling :}

The withered leaves were passed through the CTC (Crush, Tear, \& Curl) machine five times to get adequate maceration and the resultant cut dhool was passed on to fermentation.

\section{Fermentation :}

The cut dhool was spread over fermenting trays at a thickness of 1.3-1.8 inches for a period of eighty five minutes and the relative humidity was maintained between 89 and $92 \%$. Samples (cut dhool) were collected from fermenting trays at five minutes interval for detecting optimum fermentation time both by HEN and chemical method. 


\section{Drying:}

The fermented dhool was passed on to a mini fluid bed drier and hot air was blown through the tea with an inlet temperature of about $95-100^{\circ} \mathrm{C}$. After twenty minutes of drying, the dried tea with a moisture content of $2-3 \%$ was obtained. The tea was further graded used for the analysis of quality constituents. Samples of black tea were analysed for theaflavins (TF), thearubigins (TR), high polymerised substances (HPS), and total liquor colour (TLC) by Thanaraj and Seshadri, (1990) method. Water extract (WE) was estimated using Indian Standards (IS 13862:1999) and Crude fibre content (CFC) by ISO method (ISO 15598:1999 (E)).

\section{Results And Discussion:-}

This experiment was carried out in two different popular tea clones namely TRF-1( quality and high yield) and UPASI -9 (high yield and evergreen). Fermentation time of the above mentioned clones were optimized by handheld electronic nose. In fermentation room, the temperature and relative humidity were maintained at $24.5^{\circ} \mathrm{C}$ and $75 \%$ respectively during the study period. For the clone TRF - 1 the highest second peak was captured at 55 minutes and it was recorded at 65 minutes for the clone UPASI-9. Fermentation time was further extended to twenty minutes for the clones tested. The cut dhool were dried at 95 to $100^{\circ} \mathrm{C}$ for twenty minutes and further graded as BOPL, BOP and RD. The dried teas were analysed for their quality constituents such as theaflavin (TF), thearubigin (TR), high polymerized substances (HPS) and total liquor colour (TLC). It is evident from table.1 is that Theaflavin and Thearubigin were on the higher side when tea was subjected to optimum fermentation time of 55 minutes for clone TRF-1 and 65 minutes for clone UPASI- 9 when compared to 75 and 85 minutes. The cup quality was reported as good and balanced cup by the professional tasters for teas (55 mts optimized fermentation time). Whereas, it was reported as high coloured plain tea for teas were subjected to extended fermentation time (75 and 85 minutes). Total liquor colour increased when fermentation time increased. However, the theaflavin (TF) content decreased which is responsible for briskness and brightness of tea. The study also reveals that, even ten to twenty minutes variation in fermentation time leads to affect the theaflavin content in tea by 15 to 20 percent. The optimum fermentation time determined by handheld electronic nose was similar with the optimum fermentation time determined by chemical method (figure 1 and 2). Chemical method for determining optimum fermentation time require more time, chemical and also laborious process. It requires small laboratory setup in factory premises. Handheld Electronic Nose is suitable alternate machine to overcome chemical method.Hence this instrument is suitable for determine the optimum fermentation time during tea manufacturing process.

Quality of different types of black tea such as whole leaf, brokens and fannings in orthodox category and leaf, fannings and dust in CTC category were studied based on their flavor by handheld electronic nose. It was compared with the organoleptic evaluation of teas by various professional tasters. The results given in tables ( 2 to 7$)$ and figure. 3

Table 1:-Variation of quality of tea in different clones at different fermentation time detected by Handheld Electronic Nose (HEN)

\begin{tabular}{|c|c|c|c|c|c|c|}
\hline Clone & Grade & $\begin{array}{l}\text { Fermentation time } \\
\text { in Minutes }\end{array}$ & TF \% & TR \% & HPS \% & TLC \\
\hline \multirow[t]{6}{*}{ TRF-1 } & BOPL & \multirow{3}{*}{$\begin{array}{c}55 \text { (Optimised by } \\
\text { HEN) }\end{array}$} & 1.70 & 12.13 & 6.59 & 4.52 \\
\hline & BOP & & 1.84 & 10.56 & 7.15 & 4.88 \\
\hline & RD & & 1.81 & 11.15 & 8.28 & 5.37 \\
\hline & BOPL & \multirow[t]{3}{*}{75 (extended) } & 1.64 & 9.15 & 7.17 & 4.72 \\
\hline & BOP & & 1.70 & 9.75 & 7.91 & 5.28 \\
\hline & RD & & 1.72 & 10.22 & 9.25 & 5.69 \\
\hline \multirow[t]{6}{*}{ UPASI-9 } & BOPL & \multirow{3}{*}{$\begin{array}{c}65 \text { (Optimised by } \\
\text { HEN) }\end{array}$} & 1.11 & 8.41 & 7.46 & 3.94 \\
\hline & BOP & & 1.21 & 9.41 & 7.73 & 4.15 \\
\hline & RD & & 1.29 & 9.28 & 7.98 & 4.10 \\
\hline & BOPL & \multirow[t]{3}{*}{85 (extended) } & 1.03 & 8.11 & 7.74 & 4.04 \\
\hline & BOP & & 1.02 & 8.80 & 8.34 & 4.30 \\
\hline & RD & & 1.02 & 9.50 & 9.53 & 4.61 \\
\hline
\end{tabular}


Figure 1:-Fermentation Profile By Hen (Aroma Index)

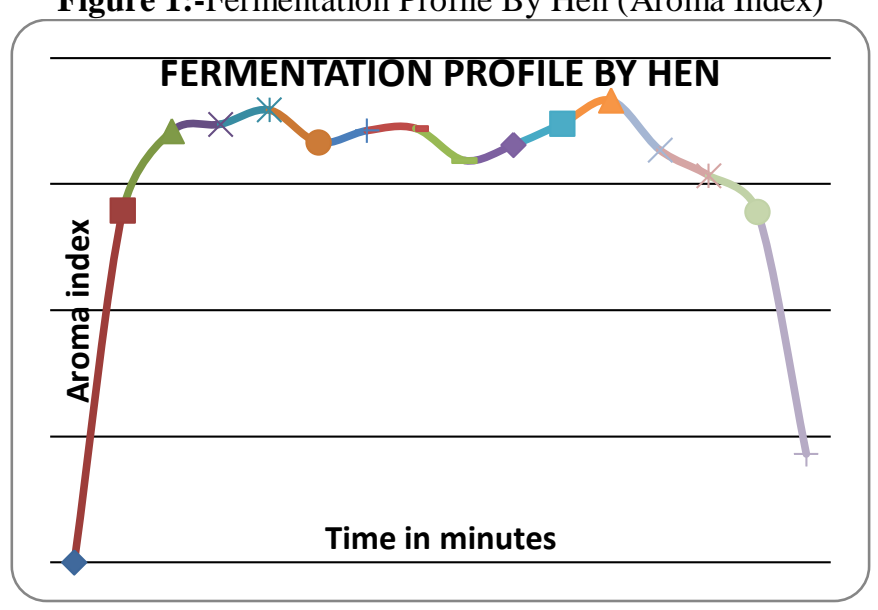

Figure 2:-Fermentation Profile By Chemical Method (Optical Density)

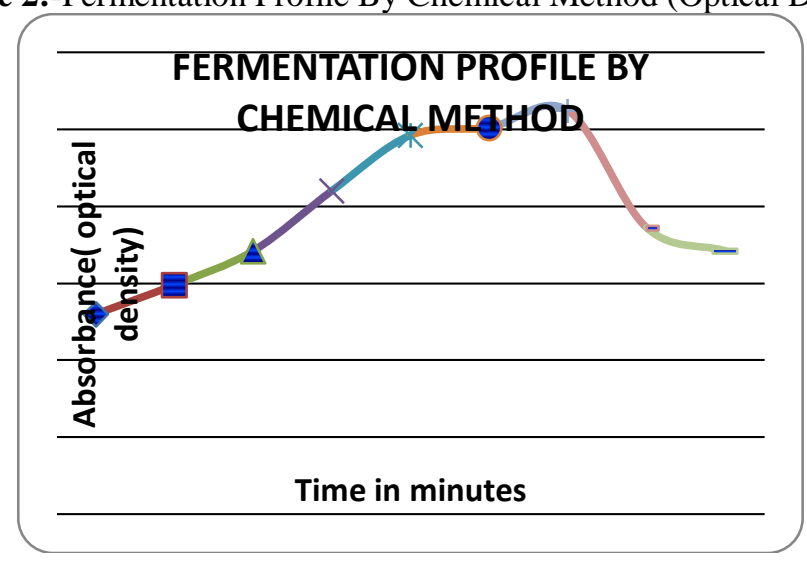

Table 2:-Organoleptic evaluation of Orthodox whole leaf by different tasters Vs Handheld electronic nose

\begin{tabular}{|c|c|c|c|c|c|c|c|}
\hline \multicolumn{5}{|c}{ TASTER } & Flavour & \multicolumn{2}{c|}{ HEN } \\
\hline $\mathbf{1}$ & $\mathbf{2}$ & $\mathbf{3}$ & $\mathbf{4}$ & $\mathbf{5}$ & Avg/10 & AS/10 & AI \\
\hline 4.00 & 3.00 & 4.00 & 2.00 & 6.00 & 3.80 & 7.28 & 14.70 \\
\hline 4.00 & 2.00 & 4.00 & 2.00 & 8.00 & 4.00 & 6.60 & 14.04 \\
\hline 4.00 & 4.00 & 4.00 & 3.00 & 5.00 & 4.00 & 5.74 & 10.94 \\
\hline 5.00 & 3.00 & 4.00 & 3.00 & 3.00 & 3.60 & 3.44 & 5.30 \\
\hline 4.00 & 1.00 & 4.00 & 2.00 & 4.00 & 3.00 & 6.11 & 11.83 \\
\hline
\end{tabular}

Table 3:-Organoleptic evaluation of Orthodox broken by different tasters Vs Handheld electronic nose

\begin{tabular}{|c|c|c|c|c|c|c|c|}
\hline \multicolumn{5}{|c|}{ TASTER } & Flavour & \multicolumn{2}{c|}{ HEN } \\
\hline $\mathbf{1}$ & $\mathbf{2}$ & $\mathbf{3}$ & $\mathbf{4}$ & $\mathbf{5}$ & Avg/10 & AS/10 & AI \\
\hline 4.00 & 1.00 & 4.00 & 2.00 & 6.00 & 3.40 & 5.20 & 9.60 \\
\hline 6.00 & 0.00 & 4.00 & 2.00 & 5.00 & 3.40 & 4.68 & 8.33 \\
\hline 4.00 & 1.00 & 4.00 & 2.00 & 7.00 & 3.60 & 3.90 & 6.42 \\
\hline 4.00 & 3.00 & 3.00 & 4.00 & 6.00 & 4.00 & 5.28 & 9.81 \\
\hline 2.00 & 0.00 & 4.00 & 3.00 & 8.00 & 4.25 & 6.06 & 11.73 \\
\hline
\end{tabular}

Table 4:- Organoleptic evaluation of Orthodox fannings by different tasters Vs Handheld electronic nose

\begin{tabular}{|l|c|c|c|c|c|c|c|}
\hline \multicolumn{5}{|c|}{ TASTER } & Flavour & \multicolumn{2}{|c|}{ HEN } \\
\hline $\mathbf{1}$ & $\mathbf{2}$ & $\mathbf{3}$ & $\mathbf{4}$ & $\mathbf{5}$ & Avg/10 & AS/10 & AI \\
\hline
\end{tabular}




\begin{tabular}{|l|l|l|l|l|l|l|l|}
\hline 3.00 & 4.00 & 4.00 & 1.00 & 4.00 & 3.20 & 4.78 & 8.58 \\
\hline 4.00 & 3.00 & 3.00 & 1.00 & 4.00 & 3.00 & 4.65 & 8.26 \\
\hline 4.00 & 5.00 & 4.00 & 1.00 & 5.00 & 3.80 & 4.27 & 7.31 \\
\hline 5.00 & 3.00 & 3.00 & 1.00 & 5.00 & 3.40 & 3.85 & 6.29 \\
\hline 5.00 & 5.00 & 4.00 & 1.00 & 5.00 & 4.00 & 5.93 & 11.41 \\
\hline
\end{tabular}

Table 5:-Organoleptic evaluation of CTC leaf by different tasters Vs Handheld electronic nose

\begin{tabular}{|c|c|c|c|c|c|c|c|}
\hline \multicolumn{9}{|c|}{ TASTER } & Flavour & \multicolumn{2}{c|}{ HEN } \\
\hline $\mathbf{1}$ & $\mathbf{2}$ & $\mathbf{3}$ & $\mathbf{4}$ & $\mathbf{5}$ & Avg/10 & AS/10 & AI \\
\hline 5.00 & 4.00 & 5.00 & 4.00 & 4.00 & 4.40 & 4.36 & 7.55 \\
\hline 6.00 & 4.00 & 5.00 & 3.00 & 5.00 & 4.60 & 5.97 & 11.50 \\
\hline 7.00 & 9.00 & 7.00 & 6.00 & 8.00 & 7.40 & 3.03 & 4.28 \\
\hline 8.00 & 9.00 & 7.00 & 8.00 & 10.00 & 8.40 & 3.50 & 5.44 \\
\hline 6.00 & 5.00 & 5.00 & 4.00 & 7.00 & 5.40 & 3.77 & 6.09 \\
\hline
\end{tabular}

Table 6:-Organoleptic evaluation of CTC fannings by different tasters Vs Handheld electronic nose

\begin{tabular}{|c|c|c|c|c|c|c|c|}
\hline \multicolumn{9}{|c|}{ TASTER } & Flavour & \multicolumn{2}{c|}{ HEN } \\
\hline $\mathbf{1}$ & $\mathbf{2}$ & $\mathbf{3}$ & $\mathbf{4}$ & $\mathbf{5}$ & Avg/10 & AS/10 & AI \\
\hline 5.00 & 4.00 & 4.00 & 2.00 & 5.00 & 4.00 & 3.71 & 5.96 \\
\hline 5.00 & 4.00 & 4.00 & 1.00 & 3.00 & 3.40 & 3.01 & 4.22 \\
\hline 4.00 & 6.00 & 4.00 & 1.00 & 5.00 & 4.00 & 3.06 & 4.36 \\
\hline 5.00 & 7.00 & 4.00 & 3.00 & 6.00 & 5.00 & 3.00 & 4.20 \\
\hline 4.00 & 4.00 & 4.00 & 2.00 & 3.00 & 3.40 & 4.25 & 7.28 \\
\hline
\end{tabular}

Table 7:-Organoleptic evaluation of CTC dust by different tasters Vs Handheld electronic nose

\begin{tabular}{|c|c|c|c|c|c|c|c|}
\hline \multicolumn{5}{|c|}{ TASTER } & Flavour & \multicolumn{2}{c|}{ HEN } \\
\hline $\mathbf{1}$ & $\mathbf{2}$ & $\mathbf{3}$ & $\mathbf{4}$ & $\mathbf{5}$ & Avg/10 & AS/10 & AI \\
\hline 5.00 & 6.00 & 4.00 & 2.00 & 5.00 & 4.40 & 3.36 & 5.10 \\
\hline 4.00 & 4.00 & 5.00 & 3.00 & 5.00 & 4.20 & 3.33 & 5.02 \\
\hline 4.00 & 5.00 & 4.00 & 2.00 & 5.00 & 4.00 & 3.13 & 4.52 \\
\hline 5.00 & 4.00 & 4.00 & 3.00 & 4.00 & 4.00 & 3.56 & 5.59 \\
\hline 4.00 & 9.00 & 4.00 & 2.00 & 6.00 & 5.00 & 5.51 & 10.36 \\
\hline
\end{tabular}

Figure 3:-Relationship between taster's score and aroma score, aroma Index derived from Handheld Electronic nose (HEN)
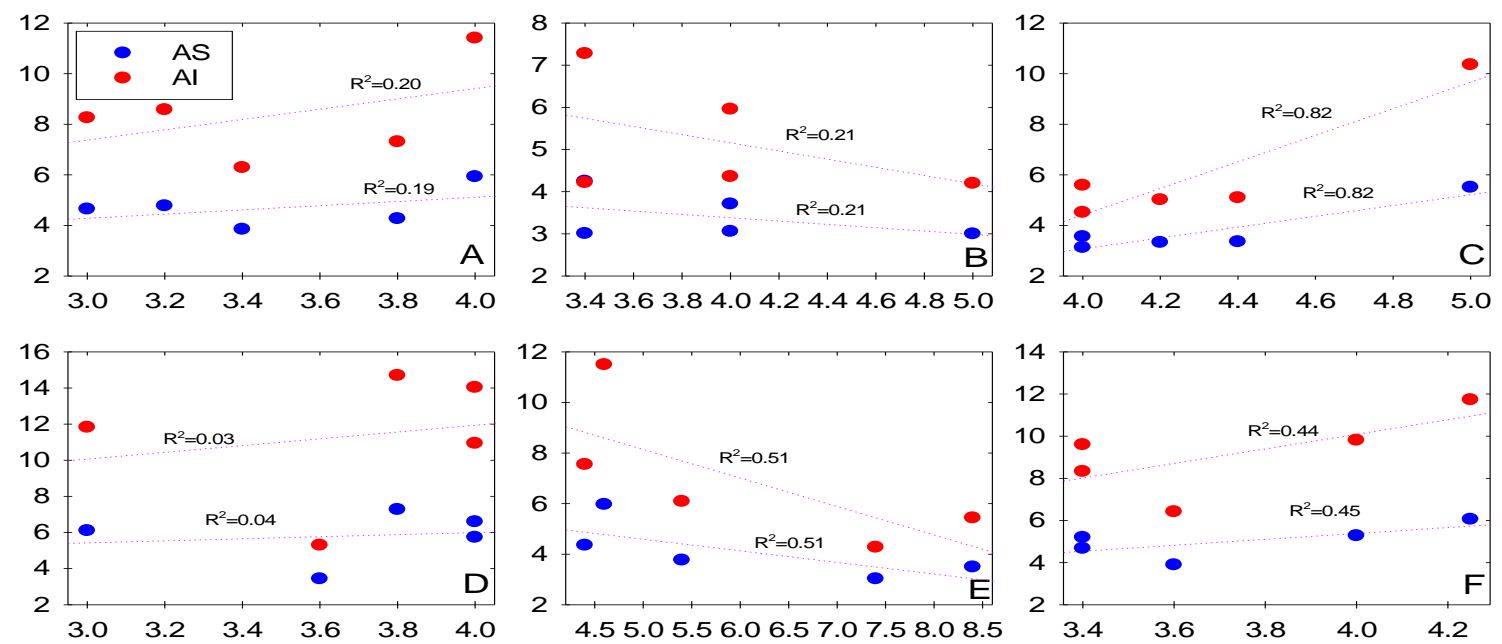

Taster's Score 
A-C: CTC black tea; D-F: Orthodox; AS: Aroma score; AI: Aroma Index; A: CTC Fannings; B: CTC Dust; C: CTC Leaf; D: Orthodox Broken; E: Orthodox Whole Leaf; and F: Orthodox Fannings; X axis: mean of five taster's score (unitless); Y axis: Aroma score and index (unitless).

\section{Acknowledgment:-}

The authors thank Dr. B.Radhakrishnan, Director, UPASI Tea Research Foundation for constant encouragement and facilities. Thanks are also due to CDAC, Kolkata for providing the instrument.

\section{References:-}

1. Bhuyan, L. P., Hussain, A., Tamuly, P., Gogoi, R. C., Bordoloi, P. K., Hazarika, M., et al.(2009). Chemical characterization of CTC black tea of Northeast India: Correlation of quality parameters with tea tasters evaluation. J.Science of food and agriculture, 89,1498- 1507.

2. Bhuyan, L. P., Borah. P, Sabhapondit. S, Gogoi. R, Bhattacharyya. P. Spatial variability of theaflavins and thearubigins fractions and their impact on black tea quality. J. Food sci Technol (Dec 2015) 52 (12); 7984-7993.

3. Biswas, A.K., and Sarkar, A. (1973). Biological and chemical factors affecting the valuation of North- East Indian plain teas. J.Science of food and agriculture. 24, 1457- 1477.

4. Ramaswamy. S. 1984. UPASI Tea Scientific Department, $58^{\text {th }}$ Annual report, Report of the Tea Tecnologist.

5. Ramaswamy. S. 1985. UPASI Tea Scientific Department, $59^{\text {th }}$ Annual report, Report of the Tea Tecnologist.

6. Ramaswamy. S. 1986. Improving tea quality in south India. UPASI Tea Scientific Department, Bulletin. 41; 1224

7. Roberts, E. A. H. (1963). The phenolic substance of manufactured tea. X. the creaming down of tea liquors. J.Science of food and agriculture. 14, $700-705$.

8. Robertson, A. The chemistry and biochemistry of black tea production - the non volatiles. in Tea: Cultivation to consumption: Wilson, K. C., Clifford, M. N., Eds.: Chapman and Hall; London, U. K., 1992: pp 555-601.

9. Thanaraj. S. N. S and Seshadri. R. 1990. Influence of polyphenols oxidase activity and polyphenols content of tea shoot on quality of black tea. J.Science of food and agriculture. 51:57-69.

10. Venkateswaran. G., Sankaran.M. S. and Hudson. J. B. 2002. Quality evaluation of black tea. The planters Chronicle, 98(7). pp. 249-252.

11. Wood. D. J. and Roberts. E. A.H. 1964. Chemical basis of quality in tea. J.Science of food and agriculture. 15:19-25. 